\title{
Conflicto por la tierra. Retorno y restitución de tierras en la finca El Carpintero (Colombia)
}

\author{
Leonardo Salamanca Ospina \\ Carmen Egea Jiménez \\ Universidad de Granada \\ teleologias@yahoo.es \\ cegea@ugr.es
}

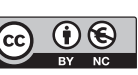

Recibido: marzo de 2017

Aceptado: noviembre de 2017

Publicado: noviembre de 2018

\section{Resumen}

La importancia del retorno de población emigrante estriba en que en casi todo proyecto migratorio está presente el regreso. La investigación de dicho fenómeno no es de las más prolíficas, aunque este se convierte especialmente en interesante cuando acontece en un contexto de conflicto y en el marco de procesos de restitución de tierras a personas que previamente han sido desplazadas y que regresan a su lugar de origen o que desean hacerlo. Esta circunstancia es la que se analiza en el caso de la finca El Carpintero, del municipio de Cabuyaro (departamento del Meta). La investigación se centra en el análisis cualitativo de documentos de naturaleza diferente, y es especialmente novedoso el de vídeos de procesos judiciales. El estudio se ha desarrollado con el programa asistido de análisis de datos CADQAS, en concreto Atlas.ti, que ha permitido, como parte de los resultados, identificar los objetos y los actores que en los procesos de retorno determinan conflictos en la restitución de tierras.

Palabras clave: retorno; restitución de tierras, conflictos por la tierra; víctimas; resolución de conflictos

Resum. Conflicte per la terra. Retorn i restitució de terres a la finca El Carpintero (Colòmbia)

La importància del retorn de població emigrant rau en el fet que en gairebé tots els projectes migratoris es té present la tornada. La investigació d'aquest fenomen no és de les més prolífiques, encara que aquest esdevé especialment interessant quan té lloc en un context de conflicte i en el marc de processos de restitució de terres a persones que prèviament han estat desplaçades i que tornen al seu lloc d'origen o que desitgen fer-ho. Aquesta circumstància és la que s'analitza en el cas de la finca El Carpintero, del municipi de Cabuyaro (departament del Meta). La recerca se centra en l'anàlisi qualitativa de documents de naturalesa diferent, i és especialment nova la dels vídeos dels processos judicials. Aquesta anàlisi s'ha desenvolupat amb el programa assistit d'estudi de dades CADQAS, en concret Atlas.ti, que permet — com algun dels resultats— identificar els objectes i els actors que, en els processos de retorn, determinen conflictes en la restitució de terres.

Paraules clau: retorn; restitució de terres; conflictes per la terra; víctimes; resolució de conflictes 
Résumé. Conflit foncier. Retour et restitution des terres dans la communauté El Carpintero (Colombie)

L'importance du retour de la population émigrante s'appuie sur le fait que la migration de retour est présente dans presque tout projet migratoire. Les recherches dans ce domaine ne sont pas des plus prolifiques, bien que le phénomène devienne particulièrement intéressant lorsqu'il s'inscrit dans un contexte de conflit et dans le cadre d'un processus de restitution des terres aux personnes déplacées au préalable, qui reviennent —ou désirent revenir- à leur lieu d'origine. C'est ce que nous nous proposons d'analyser dans le cas du domaine El Carpintero sur la municipalité de Cabuyaro (Département de la Meta). La recherche se centre sur l'analyse qualitative de documents de différentes natures, et sur une approche innovante par l'usage de vidéos des processus judiciaires. L'analyse a pu être développée grâce à un programme d'analyse de données (CADQAS) Atlas.ti, permettant —entre autres - d'identifier les objets et les acteurs qui, durant le processus de retour, occasionnent des conflits lors de la restitution des terres.

Mots-clés: retour; restitution de terres; conflits fonciers; victimes; résolution de conflits

Abstract. Land conflict: Return and restitution of land in El Carpintero farm (Colombia)

The importance of returning for emigrant populations is evidenced by the fact that return is present in almost every migratory project. Although there is a scarcity of research on this topic, it is especially interesting when return occurs in a context of conflict and in the framework of processes to restitute land to people who have previously been displaced and who return - or want to return - to their place of origin. This study specifically examines the case of El Carpintero farm in the municipality of Cabuyaro (Department of Meta, Colombia) through a qualitative analysis of documents of different kinds, particularly the novel use of videos of judicial processes. The analysis is performed using ATLAS.ti computer-assisted qualitative data analysis software (CADQAS), which has enabled identifying the objects and actors that, in return processes, determine land restitution conflicts.

Keywords: return; land restitution; land conflicts; victims; conflict resolution

\section{Sumario}

\section{Introducción 5. Metodología}

2. El conflicto por la tierra en Colombia

6. Análisis de resultados

3. El retorno de población desplazada

7. Conclusiones

en medio del conflicto

Referencias bibliográficas

4. El contexto legal del retorno: La Ley de víctimas y restitución de tierras 1448

\section{Introducción}

Este estudio se basa en el análisis del conflicto por la tierra en la finca El Carpintero en el contexto del retorno de personas desplazadas. La finca se ubica en la vereda de Yarico (municipio de Cabuyaro, departamento del Meta), región 
caracterizada por una historia de cambios demográficos asociados a procesos de colonización. A inicios del siglo XX era frecuente en esta región el despojo de tierras debido a la caza y a las masacres de indios perpetradas por colonos y hacendados (Gómez, 1998). Este escenario aumentó su complejidad con el asentamiento de campesinos desplazados que huían de la violencia partidista de la década de 1940. A ellos se sumaron, en las décadas de 1960 y 1970, los extranjeros y los grandes ganaderos que acumularon tierras en medio de la matanza de indígenas (La Rota y Salcedo, 2016).

En la región, el conflicto armado se caracterizó por la presencia del bloque oriental de las Fuerzas Armadas Revolucionarias de Colombia-Ejército del Pueblo, que, a finales de los años setenta, contaban con cuatro frentes en los departamentos del Meta y Caquetá. A partir de la década de 1980 la emergencia de los grupos paramilitares y el interés de esta zona como corredor estratégico para cultivos asociados al narcotráfico posibilitaron el control y la acumulación de tierras por parte de personajes como Víctor Carranza y de narcotraficantes como Leónidas Vargas, Carlos Leder y Rodríguez, que compraron miles de hectáreas en el norte del Meta (La Rota y Salcedo, 2016; Rodríguez, 2014).

Organismos internacionales como la Defensoría del Pueblo reconocen a esta zona como de alto riesgo, y han emitido de forma reiterada informes de alertas relacionadas con la presencia de grupos armados de las Autodefensas Unidas de Colombia — Bloque Meta y Libertadores del Vichada-; la existencia de ejércitos privados pagados por esmeralderos y traficantes que expulsaron a colonos y se apropiaron de tierras; la incertidumbre en los derechos de propiedad, y la importancia de estos territorios para la economía nacional (Defensoría del Pueblo, 2016).

La región de la altillanura se considera una de las zonas con más proyección económica por su potencial petrolífero y el cultivo de palma para biodiésel. Algunas investigaciones sugieren que las narrativas estatales han sustentado la idea de que se trata de un territorio sin tradiciones culturales indígenas o campesinas y con un potencial agroecológico nulo por la acidez de los suelos. Estas ideas han servido para sustentar grandes proyectos económicos en esta región.

El Carpintero es una propiedad con una extensión de 1.038 hectáreas adjudicada en 1997 a 85 familias por el Instituto Colombiano de Reforma Agraria (INCORA). La adjudicación fue mediante una compra subsidiada por dicho organismo que cubrió el $70 \%$ de su valor y dejó el 30\% como deuda asumida por dichas familias. De las 85 familias, 40 provenían de municipios de Restrepo y Cumaral damnificadas por los estragos de lluvias torrenciales y las otras 45 eran víctimas de procesos de despojo y de desplazamiento forzado desde diferentes regiones del país.

Las familias quedaron en una situación de abandono desde el mismo momento del asentamiento, el 27 de diciembre de 1997. El Estado se limitó a comprar la finca como venta de común proindiviso, que consiste en que varias partes adquieren un mismo bien sin especificar la división del mismo. Así, las familias quedaron expuestas a conflictos cuando llegó el momento de delimitar la propiedad de la tierra. Entre ambos grupos acordaron dividir el predio en 
dos partes, una para los damnificados y otra para los desplazados. Sin embargo, la irrupción de grupos paramilitares minó la posibilidad de vivir en el territorio. Las familias desplazadas sufrieron el hostigamiento de los paramilitares mediante amenazas y fueron etiquetados de guerrilleros, con la presunta complicidad de las familias damnificadas. El asesinato, a finales de 1998, de una persona desplazada generó un nuevo desplazamiento, esta vez progresivo, al descubrirse una lista con el nombre de diferentes líderes que corrían el riesgo de ser también asesinados (Espinel y Pinzón, 2014).

Como resultado, las 45 familias desplazadas tuvieron que emprender una nueva migración forzosa. La identificación de los lugares de reasentamiento de estas familias no ha sido fácil, puesto que el movimiento fue esporádico y no grupal. Para esta investigación se accedió a los testimonios de familias que viven en Bogotá y algunas de Villavicencio, pero es imposible saber la intención de retorno del total de las que se encuentran en otras regiones. Esta dificultad es un hecho que se presenta en casi todas las investigaciones sobre movimientos migratorios de retorno: ¿cuántas personas de las que emigran piensan retornar?, ¿cuántas finalmente lo harán?

A lo anterior se suma que, desde 1998, solo una familia intentó regresar a El Carpintero, pero de nuevo recibió amenazas. El tiempo de desplazamiento ha hecho que las familias diversifiquen sus estrategias a la hora de pensar en el regreso, ya que pesa el desarraigo y la actitud de los jóvenes, que no siempre se muestran interesados en volver. En la actualidad este proceso se acoge a la Ley de restitución de tierras 1448. La comunidad espera un fallo favorable a su solicitud de retorno, de reasentamiento u otra alternativa.

\section{El conflicto por la tierra en Colombia}

Las investigaciones que tratan el conflicto por la tierra lo señalan como un problema de origen colonial relacionado con el poblamiento de regiones baldías y el proceso de apropiación espontánea (CNMH, 2016). A finales del siglo XIX existían conflictos de este tipo en el territorio colombiano, y aunque había leyes que favorecían la adjudicación gratuita de tierras a quienes cultivaban las baldías, los costes de los trámites de formalización de propiedad hacían imposible su apropiación real.

En contraposición, las élites aprovecharon su poder para apropiarse de la tierra utilizando métodos de desposesión frente a los colonos, solicitaron al gobierno su adjudicación o bien cercaron lotes inmensos. Esta práctica aumentó la extensión de las fincas, además los juicos para clarificar las propiedades estuvieron plagados de facturas de venta, documentos de herencia y escrituras notariales que el sistema judicial colombiano aceptó sin cuestionar su legitimidad. Los baldíos pasaron de facto a ser propiedad privada (Legrand, 2009). Las investigaciones no definen el verdadero éxito de las resoluciones legales, pero la configuración de la tenencia de la tierra permite entrever que los hacendados, a pesar de la resistencia de los campesinos, reforzaron la concentración de la tierra. 
En las primeras décadas del siglo XX este conflicto se caracteriza por la resistencia de colonos y campesinos sin tierra. En las zonas rurales, los litigios jurídicos, el no pago de la renta y las invasiones de tierra fueron comunes (Marulanda, 1988), a raíz de lo cual surgieron las primeras organizaciones campesinas como la Colonia Agrícola de Sumapaz. Por su parte, el Estado estableció la Ley 200/1936, considerada la primera reforma agraria moderna de Colombia. Su aporte fue situar en primer plano la función social de la tierra. Otorgar títulos no era solamente una decisión administrativa, sino también de carácter político, lo que amenazó al latifundio (Molano, 2014). Por este motivo aumentaron los conflictos entre hacendados y colonos, y supuso un precedente del periodo de violencia (1950 a 1965) vivido en las regiones rurales entre los campesinos liberales y la policía conservadora. El resultado fue el destierro de campesinos, lo que favoreció la readecuación de la propiedad de la tierra de acuerdo con el modelo capitalista que empezaba a gestarse con la producción agroindustrial (Soledad, 2009). Este periodo reconfiguró el sistema migratorio interno y Colombia pasó de ser un país rural a un país con altos índices de población urbana, del $31 \%$ en 1938 pasó al 65\% en 1985 (Cuervo y Jaramillo, en Sánchez, 2008).

En la historia reciente del país, el territorio colombiano puede considerarse un espacio de poder (Egea y Soledad, 2007), lo que implica que los actores armados se apropian de los planes de vida de las comunidades al adueñarse de territorios con un inigualable interés geoestratégico para tráfico de drogas, potencial de recursos naturales y minerales y cultivo agroindustrial. Por otra parte, también se han adueñado de las zonas rurales grupos económicos extranjeros y multinacionales con el apoyo de grupos paramilitares. De esta manera, estos espacios de poder lo son también del miedo, ya que los actores armados presionan a través de redes de informantes con campañas de «limpieza social», extorsiones y obligación de pago de impuestos de guerra. Esta «cotidianidad» conlleva una acumulación de tierras que propicia el desplazamiento (Ibáñez y Querubín, 2004).

Así, el análisis de la pugna por la tierra se considera un tema primordial para entender la raíz del enfrentamiento colombiano. Algunos enfoques hacen énfasis en los conflictos de propiedad y uso del suelo, al acentuar la concentración y el control territorial, lo que genera el desplazamiento de la población rural y el despojo de sus pertenencias — principalmente la tierra- (Machado, 2004).

Otros enfoques resaltan temas asociados al modelo de desarrollo económico como actividades extractivas de los megaproyectos, lo que posibilita que las élites regionales se adueñen de los territorios, con lo que se reducen las posibilidades de trabajo de la población campesina transformada en mano de obra itinerante en mercados laborales circulares entre campo y ciudad (Fajardo, 2004). No faltan análisis que ponen el acento en el recrudecimiento del conflicto armado, el cual esconde sus raíces en el poder paramilitar y su impacto en el desplazamiento forzado como una de las principales consecuencias (Romero, 2010; Nodgren, 2000; Churruca y Meertens, 2010). En la 
misma línea, Zuluaga (2009) destaca la violación de derechos humanos y del derecho internacional humanitario que compromete a los diferentes actores armados en el conflicto.

\section{El retorno de población desplazada en medio del conflicto}

A pesar de que el retorno no es de los tipos de emigración más investigados y menos aún en contextos de conflicto, los estudios existen y suponen una línea de trabajo todavía novedosa. Así, destacan estudios sobre el retorno de refugiados guatemaltecos (Rousseau et al., 2001) exiliados sudafricanos después del apartheid (Steyn y Grant, 2007), refugiados palestinos (Hanafi, 2003; Isotalo, 2005) de Kosovo (Pavlakovi, 2000) y de Bosnia Herzegovina (Dahlman y Tuathail, 2005; Hadzic, 2007; Tuathail, 2010). Los temas se centran en las dificultades que sufren las personas refugiadas para regresar e integrarse socialmente; en el papel de la comunidad internacional en lo que respecta a programas de ayuda para la población retornada, y en la renovación de los conflictos en escenarios de retorno en los que, pese a las firmas y a los acuerdos de cese al fuego, las comunidades siguen siendo víctimas de acciones delictivas.

De la complejidad de estos procesos es ejemplo Guatemala, que, tras los Acuerdos de Paz de Esquipulas (1986), impulsó el plan Reasentamientos de Poblaciones Desarraigadas. Se estima que retornaron unas 41.413 personas. Principalmente se trataba de indígenas ubicados en el sur de México y 6.729 desplazados internos. No obstante, en la etapa de postconflicto, la falta de una política agraria y de un catastro rural produjo desigualdades en el acceso a la tierra y surgieron nuevos conflictos en zonas sin fronteras definidas. Se estimó que «el 5\% de los productores controlaba el 80\% de tierra cultivable» (Camacho 1999, en Gammage y Worley, 2002: 15).

En Perú, desde 1995, el retorno de personas desplazadas se gestionó desde el Programa de Apoyo al Repoblamiento, que consistió en ayudas para financiar el transporte, la entrega de víveres por seis meses, la prestación de servicios de salud antes del viaje y el acompañamiento del Ejército. Los resultados arrojaron que la reinserción fue frágil y no se establecieron cambios para una integración económica y social. Así, cinco años después, «el $80 \%$ de los retornados utilizaron recursos propios y solo el 10\% recibió apoyo del estado» (Díaz y Zamora, 2010: 178).

Otros estudios analizan la memoria y los imaginarios del retornado (Steyn y Grant, 2007). Un ejemplo es la importancia que las comunidades guatemaltecas otorgaban a la tierra (Stepputat 1994, en Rousseau et al., 2001). Otras investigaciones señalan los relatos del retorno palestino como visión hegemónica y elemento unificador del Estado nación, convirtiéndolo en un discurso nacionalista de la diáspora palestina (Isotalo, 2005) con lo que se asoció retorno y lucha palestina.

En Colombia este tema es relativamente reciente y coincide con el desarrollo jurídico en materia de desplazamiento forzado y retorno. Las áreas geográficas estudiadas son los departamentos de Sucre, Bolívar, Cesar, Antioquia, 
Chocó y algunas zonas del centro y del sur de los departamentos Valle del Cauca, Cauca y Meta. De 1999 a 2016 hay dos fases en la forma de abordar el tema. En la primera (1999-2010) se analizan las políticas públicas y la atención al desplazado; en la segunda, desde 2011, la restitución de tierras y la reparación de víctimas. En las dos fases hay un tema transversal: la situación de los derechos humanos. Las orientaciones temáticas se ubican en distintos escenarios: el retorno de población refugiada (Santacruz, 2013; López, 2007; Salazar, 2009; Perdomo y Clavijo, 1999); el deseo y las intenciones de volver (Chávez y Falla, 2005; Perdomo y Clavijo, 1999); la dificultad de regresar en el contexto del conflicto (Salazar, 2009); la posibilidad de retornar en relación con elementos materiales de bienestar social y económicos (Saiz, 2001; Ibáñez y Querubín, 2004); la desactivación de las causas del desplazamiento, y el acompañamiento estatal en proyectos de infraestructura y de garantías de protección (Ibáñez, 2004; Velásquez, 2005). No obstante, el retorno puede darse sin ninguno de estos elementos, tal como sucede en El Catatumbo (PCS 2003, en Egea y Soledad, 2007).

Otra línea de investigación critica las políticas públicas para retornados por su enfoque asistencialista (Ibáñez, 2009). Estas investigaciones resaltan la desconexión de las instituciones locales con las propuestas de atención elaboradas a nivel nacional (Ramírez, 2015; Piedad et al., 2006). Otros estudios destacan los procesos de resistencia y las acciones comunitarias con la delimitación de zonas humanitarias (Peña, 2004; CAVIDA, 2002).

El retorno también se aborda desde una perspectiva histórica (Varón, 2011), una perspectiva teológica (Рeña, 2004) o como generador de memoria a partir de narrativas (Garzón, 2014). Por último, está el interés en el retorno asociado a la dinámica propia del conflicto armado y el papel desempeñado por los actores armados (Cantor, 2010; Varón, 2011). Además, están los estudios de organizaciones mundiales como Human Rights Watch, Amnistía Internacional y el Centro Toledo para la Paz, que resaltan la falta de garantías de seguridad que otorga la Ley de víctimas 1448 y las falencias del Estado para la puesta en práctica de una política de reparación desde la integración comunitaria (Barreto et al., 2016; Ramírez, 2015).

Finalmente, es preciso señalar la complejidad del retorno como fenómeno demográfico empezando por su definición, cuya concreción es territorial (volver al lugar de donde se sale) y también emocional (volver al lugar del que uno se siente parte) (Pascual, 2009; Egea et al., 2002). Es decir, retornar tiene que ver con la distancia recorrida y con el sentido del lugar. Esta reflexión toma mayor importancia al tratarse del retorno de población desterrada: el regreso puede significar la recuperación de un espacio físico, pero sobre todo de los proyectos de vida truncados.

En este trabajo el retorno se asume en el contexto de la restitución de tierras vinculado con el sentido del lugar, que implica ir más allá de restituir la propiedad y se relaciona con elementos simbólicos, culturales y políticos: «yo no les tengo miedo y voy a convidar a mis otros compañeros y vamos a venir hasta las tierras [...]»(DOC/P1:41). 


\section{El contexto legal del retorno: La Ley de víctimas y restitución de tierras 1448}

El retorno es un tema presente en la legislación colombiana. La Ley 387, de 1997, lo posicionó como derecho en el artículo 2. En la Ley 1448/2011, de víctimas y restitución de tierras, el retorno se asocia al escenario de la reparación de víctimas y establece como condición para el regreso que este sea voluntario. De acuerdo con la ley, el Estado debe garantizar el goce efectivo de derechos a través de esquemas de acompañamiento, se reconoce que las víctimas en el exterior pueden acceder a los beneficios de esta ley y se enfatiza que la restitución de tierras es independiente de si se produce o no el retorno.

Para entender el planteamiento del retorno como un derecho y su incidencia en el conflicto, se identifican tres fases:

1. Emergencia de la categoría en el derecho internacional. Desarrollada desde el fin de la Segunda Guerra Mundial hasta la década de 1980 (figura 1), se enmarca en el impulso de los derechos humanos desde las Naciones Unidas y la promoción de los refugiados como sujetos de derecho. El desarrollo de los derechos humanos posicionó el retorno como una facultad asociada a los derechos civiles y políticos. En esta fase no aparece el retorno como respuesta a la situación de personas afectadas por el desplazamiento interno, ya que la guerra fría invisibilizó parcialmente los conflictos internos en varias regiones del mundo.

Figura 1. Emergencia de la categoría retorno en el derecho internacional

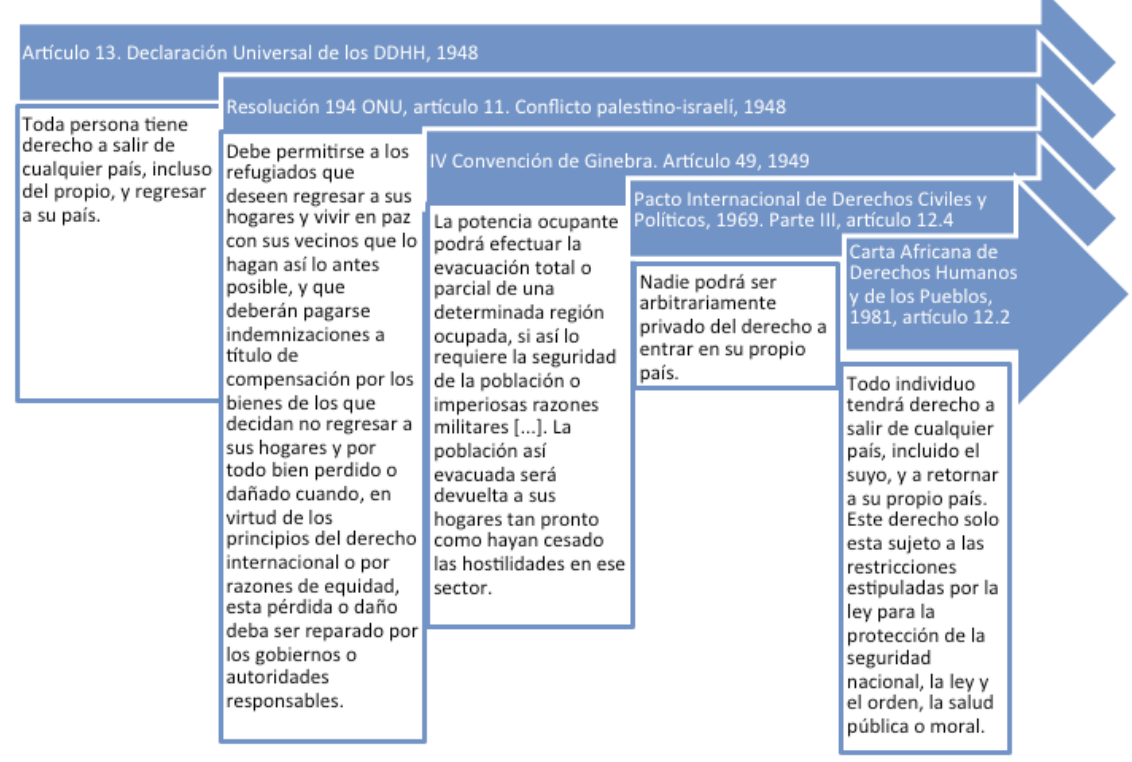

Fuente: elaboración propia. 
2. Emergencia de la categoría en relación con el desplazamiento forzado interno. A finales de 1990 fueron emergiendo diferentes principios para abordar el desplazamiento interno como un fenómeno cada vez más visibilizado. Se diseñan por primera vez instrumentos para abordar el regreso de población desplazada en un momento en que la categoría desplazamiento forzado por la violencia responde a la necesidad de contener los flujos migratorios internacionales (Vidal, 2007). Los Principios Deng y los Principios Pinheiro permiten caracterizar el regreso desde el ámbito de la reparación y de la restauración (figura 2).

3. Emergencia de la categoría en el plano jurídico nacional (figura 3). La preocupación que despertó el desplazamiento interno a nivel internacional hace que Colombia empiece a desarrollar mecanismos para afrontar esa situación desde 1997 con la Ley 387. No obstante, la sentencia T-095 de 2004 de la Corte Constitucional afirmó que la situación vivida en Colombia por el desplazamiento era un «estado de cosas inconstitucional» y obligó al Gobierno a crear la Comisión de Seguimiento de la Política Pública sobre Desplazamiento Forzado, que emitió informes mensuales desde 2007. La sentencia estableció además un sistema de información de población desplazada que registra también a personas retornadas y reubicadas.

Actualmente, la Ley de víctimas 1448 espera ser la institución central en los dictámenes de política pública en los acuerdos de paz a los que se llegue para dar respuesta a la problemática del retorno de población desplazada. Fuera del conflicto, la Ley 1565, de 2012, centrada en el retorno de colombianos en el extranjero, responde a la situación de crisis económica en países con tradición

Figura 2. Emergencia de la categoría retorno en relación con el desplazamiento forzado interno
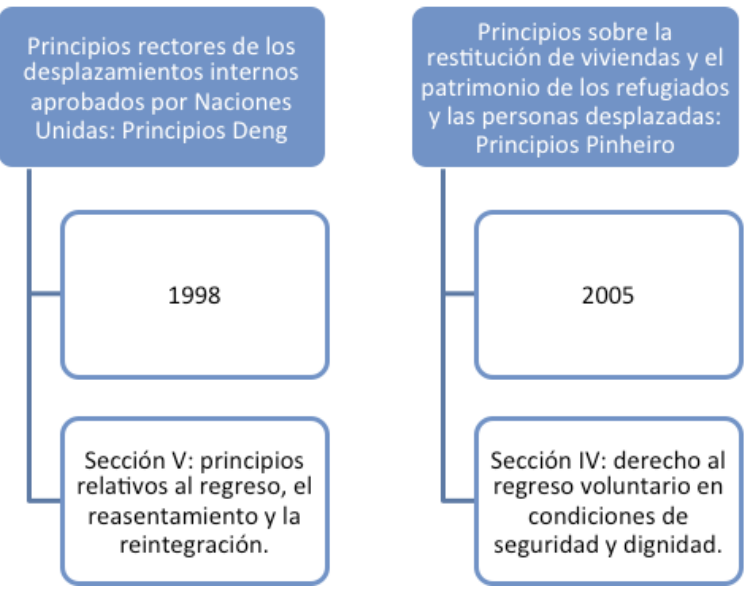

Fuente: elaboración propia. 
Figura 3. Emergencia de la categoría retorno en el plano jurídico nacional

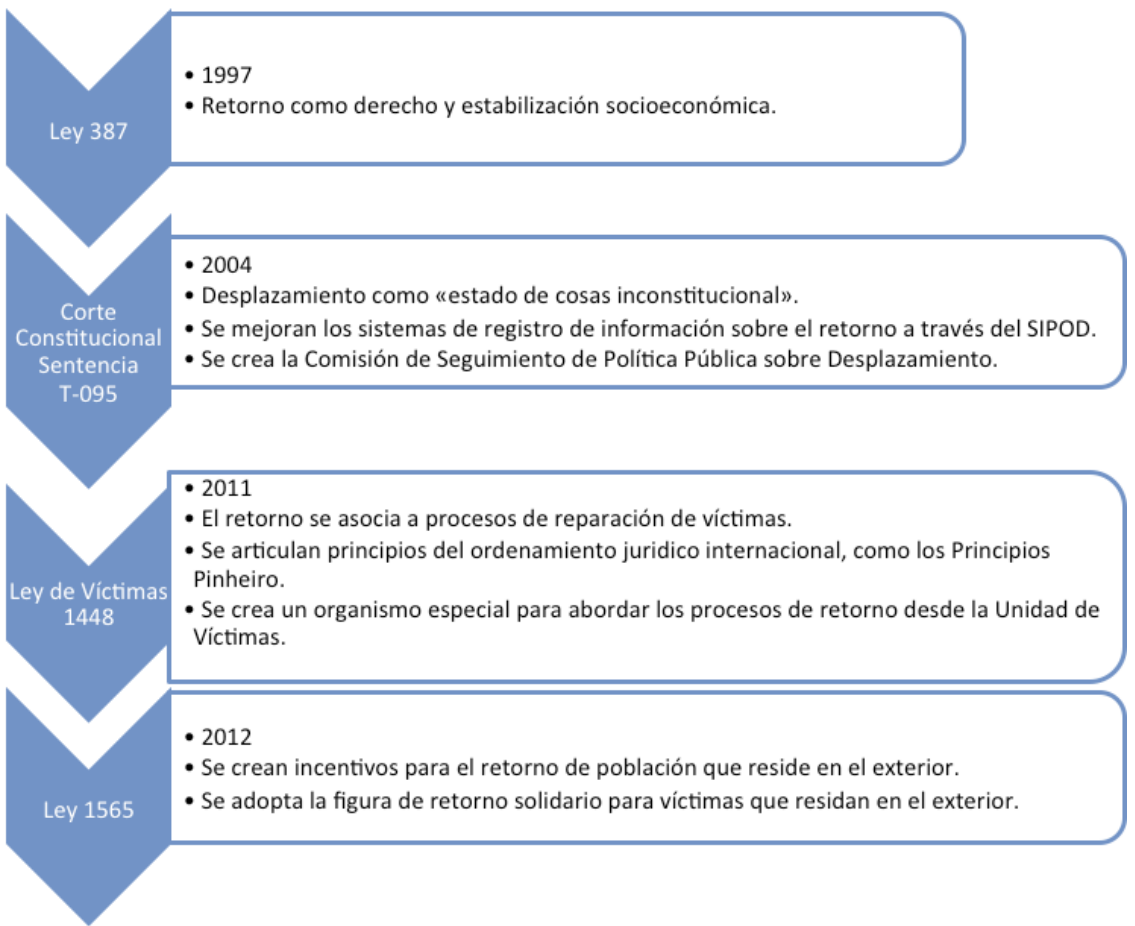

Fuente: elaboración propia.

en la recepción de inmigrantes colombianos, en especial europeos y norteamericanos, que desde hace un tiempo «invitan» a la población inmigrante a que regrese a su país. En lo que respecta al refugio, esta ley se articula a lo dispuesto en la Ley de víctimas 1448 bajo la categoría retorno solidario, entendido como el que realiza la víctima del conflicto armado interno.

\section{Metodología}

La metodología se basa en el análisis de vídeos de procesos judiciales y entrevistas en profundidad realizadas a personas desplazadas. Los vídeos, en el marco de restitución de tierras, recaban información de la fase judicial en la que se recogen acciones probatorias para establecer los hechos del despojo y formular un fallo. Aquí son relevantes las inspecciones oculares, puesto que suponen visitas que fija el juez de restitución para especificar las condiciones en las que se encuentra la finca en litigio.

En El Carpintero se realizaron dos visitas, en noviembre de 2014 y en enero de 2015, con una duración de tres días cada una. El procedimiento de inspec- 
ción ocular consistió en la presentación a la comunidad de los funcionarios y las personas que iban a acompañar la inspección, en la explicación por parte del juez sobre el objetivo de las visitas y la dinámica que llevarían a cabo, en las visitas a los predios y en las entrevistas con jefes de familia.

Las visitas fueron grabadas por un funcionario de la Unidad de Víctimas y Restitución de Tierras y los vídeos se utilizaron como material probatorio del caso. La información recogida es fundamental para conocer las versiones y los imaginarios de la comunidad que reside en el predio, cuyos miembros son considerados opositores. Dicha información tiene un valor agregado por las dificultades de acceso que presenta, hasta tal punto que es posible que sea la primera investigación sobre el tema en la que se usa ese material. Otra documentación examinada ha sido la constituida por las entrevistas a cuatro víctimas que residen en Bogotá y Villavicencio con la «condición de desplazadas», los diarios de campo y una entrevista a la abogada que representa a las víctimas en el proceso. El conjunto del material se ha estudiado mediante un programa asistido de análisis de textos (CADQAS), en concreto, Atlas.ti. Se trata en total de 16 documentos primarios (DP): 5 entrevistas, 4 diarios de campo y 7 vídeos de inspección ocular de aproximadamente 14 horas de registro.

El primer paso en el análisis ha sido segmentar y codificar los textos transcritos de las entrevistas y los audios, lo cual ha permitido identificar ejes temáticos (tabla 1). La frecuencia de códigos según ejes temáticos permite ubicar los temas recurrentes o centrales por su incidencia en la configuración de escenarios de retorno y conflictos por la tierra. Esta mirada estadística induce algunas ideas que guían el análisis: de los siete ejes temáticos, el más recurrente es acciones del Estado (al aparecer en 10 DP de un total de 16), aunque el de mayor frecuencia es el de transacciones de tierra, aun cuando solo aparece en los documentos audiovisuales; el paramilitarismo es importante en los relatos de las víctimas del despojo e ínfima en documentos relacionados con la inspección ocular; las referencias al cultivo de palma, al remanente ${ }^{1}$, a la informalidad de la tierra y al retorno se caracterizan por estar más concentradas en un tipo de documentos y dispersas en otros.

Las personas desterradas refieren con más frecuencia los asuntos relacionados con el paramilitarismo y las posibilidades de retorno, mientras que los ocupantes del predio atribuyen a las transacciones de la tierra y al remanente una importancia nodal en el conflicto. Así, queda claro que los intereses y los imaginarios que se tienen sobre el conflicto no son homogéneos, por lo que es necesario conocer qué elementos tienen más peso a la hora de resolverlo.

Con este análisis se realiza un acercamiento al sentir de informantes que, por cuestiones logísticas de la investigación, no pudo ser mayor por la dificultad de viajar hasta los lugares donde se localizan las familias. No obstante, cada DP permitió ubicar temas relacionados con la intención de regreso de la comunidad desterrada. Precisamente, algunos diálogos explicitan la idea del

1. Remanente hace referencia a la tierra que dejaron las personas desplazadas y que fue repartida a las personas que se quedaron. 
Tabla 1. Frecuencia de códigos en cada documento primario*

\begin{tabular}{|c|c|c|c|c|c|c|c|c|c|c|c|c|c|c|c|c|c|}
\hline \multirow{4}{*}{\begin{tabular}{l}
\multicolumn{1}{c}{ Códigos / } \\
Ejes temáticos \\
Transacciones \\
de tierra
\end{tabular}} & \multicolumn{16}{|c|}{ Documentos primarios (DP) } & \multirow{4}{*}{$\begin{array}{c}\text { Total } \\
\text { DP } \\
16 \\
58\end{array}$} \\
\hline & \multirow{2}{*}{\multicolumn{5}{|c|}{$\frac{\text { Entrevistas }}{\text { DP1 DP 2DP } 3 \text { DP4 DP5 }}$}} & \multicolumn{7}{|c|}{ Vídeos de inspección judicial } & \multicolumn{4}{|c|}{ Diarios de campo } & \\
\hline & & & & & & $\overline{\mathrm{DP} 6}$ & DP7 & DP8 & DP9 & $P 10$ & P 11 & $\overline{P P 12}$ & DP 13 & 14 & 15 & 16 & \\
\hline & 0 & 0 & 0 & 0 & 0 & 10 & 0 & 20 & 3 & 5 & 10 & 10 & 0 & 0 & 0 & 0 & \\
\hline $\begin{array}{l}\text { Acciones } \\
\text { del Estado }\end{array}$ & 18 & 0 & 1 & 1 & 6 & 6 & 1 & 0 & 3 & 3 & 0 & 1 & 1 & 0 & 0 & 0 & 41 \\
\hline Paramilitarismo & 10 & 13 & 4 & 4 & 1 & 1 & 0 & 0 & 0 & 0 & 0 & 1 & 1 & 0 & 0 & 0 & 35 \\
\hline Remanente & 0 & 0 & 0 & 0 & 0 & 11 & 5 & 4 & 5 & 2 & 1 & 1 & 0 & 0 & 0 & 0 & 29 \\
\hline Retorno & 5 & 4 & 3 & 6 & 3 & 1 & 0 & 0 & 0 & 0 & 0 & 0 & 0 & 1 & 2 & 0 & 25 \\
\hline $\begin{array}{l}\text { Cultivo } \\
\text { de palma }\end{array}$ & 1 & 4 & 0 & 0 & 0 & 5 & 1 & 1 & 0 & 1 & 3 & 4 & 0 & 0 & 0 & 1 & 21 \\
\hline $\begin{array}{l}\text { Informalidad } \\
\text { de la tierra }\end{array}$ & 3 & 0 & 0 & 0 & 0 & 7 & 2 & 2 & 3 & 1 & 2 & 0 & 0 & 0 & 0 & 0 & 20 \\
\hline Total & 37 & 21 & 8 & 11 & 10 & 41 & 9 & 27 & 14 & 12 & 16 & 17 & 2 & 1 & 2 & 1 & 229 \\
\hline
\end{tabular}

Fuente: elaboración propia.

* Las entrevistas DP1 a DP4 se aplicaron a víctimas; la DP5, a la abogada del caso. El código DP13 se refiere a los diarios de campo de un encuentro informal con el abogado de la oficina de Restitución de Tierras de Villavicencio; el DP14 responde a un taller con 6 familias y acompañamiento de la organización Corporación Claretiana Norman Pérez Bello; los DP15 y DP16 corresponden a dos visitas a los lugares de residencia de dos familias víctimas del caso; los DP6 a DP12 son los vídeos de la inspección judicial.

retorno como algo imposible por la realidad ineludible que lo acompaña: la expropiación. Sin embargo, el anhelo por recuperar el lugar del que fueron despojados es una idea presente y asociada al sueño del retorno. Así, un mismo informante puede anhelar el regreso y a la vez vislumbrarlo con preocupación, al no ver garantizada dicha posibilidad.

Este análisis se completa con el del material audiovisual. La tabla 2 se presenta como una matriz de secuencias narrativas (codificación de fragmentos - citas- de audio).

El material audiovisual cuenta con la siguiente secuencia narrativa: entrevista abierta del juez para determinar el tiempo de ocupación del predio, procedimiento de adquisición de los terrenos (venta, permuta, herencia), precio en las transacciones de tierra, extensión de la propiedad de cada campesino, actividad económica de las familias, cultivos y explotación en cada finca y características de la vivienda (materiales, distribución, equipamientos y servicios). Después de esta fase se establecen linderos, características y amplitud del terreno. Solo en algunas ocasiones se pregunta sobre el litigio de restitución de tierras.

La inspección parte de un mapa de las fincas realizado por los funcionarios de la Unidad de Restitución de Tierras (URT) y del Instituto Geográfico Agustín Codazzi. El levantamiento cartográfico se realiza cuando la URT notifica a los campesinos que el predio entra en proceso de restitución de tierras. Este mapa permite cotejar la información cartográfica con la realidad del momento, destacándose la realización de nuevas ventas, la llegada de nuevos campesinos al predio, problemas de clarificación de propiedad, etc. 
Tabla 2. Matriz de observación del material audiovisual

\begin{tabular}{|c|c|c|c|c|c|c|}
\hline $\begin{array}{c}\text { Secuencias } \\
\text { narrativas }\end{array}$ & Situación & Objetos & $\begin{array}{l}\text { Definiciones y } \\
\text { calificaciones }\end{array}$ & Actores & Lugares & $\begin{array}{c}\text { Notas y } \\
\text { observaciones }\end{array}$ \\
\hline $\begin{array}{l}\text { Tiempo de inicio } \\
\text { y tiempo final. }\end{array}$ & $\begin{array}{l}\text { Descripción } \\
\text { breve de lo } \\
\text { que pasa en } \\
\text { la secuencia } \\
\text { narrativa. }\end{array}$ & $\begin{array}{l}\text { Representacio- } \\
\text { nes de temas y } \\
\text { de cómo apare- } \\
\text { cen formulados, } \\
\text { cómo se expli- } \\
\text { can y cómo se } \\
\text { conciben. }\end{array}$ & $\begin{array}{l}\text { Se indaga } \\
\text { sobre la toma } \\
\text { de posición } \\
\text { con respecto a } \\
\text { los objetos, los } \\
\text { procesos de } \\
\text { legitimación, de } \\
\text { nominación y } \\
\text { de articulación. }\end{array}$ & $\begin{array}{l}\text { Son los sujetos } \\
\text { que, desde el } \\
\text { punto de vista } \\
\text { de la interac- } \\
\text { ción y la acción } \\
\text { comunicativa, } \\
\text { aparecen en las } \\
\text { secuencias. }\end{array}$ & $\begin{array}{l}\text { Descripción de } \\
\text { los lugares en } \\
\text { donde se desa- } \\
\text { rrolla la secuen- } \\
\text { cia narrativa. }\end{array}$ & $\begin{array}{l}\text { Reflexiones que } \\
\text { se pueden rea- } \\
\text { lizar mientras } \\
\text { se está viendo } \\
\text { la secuencia } \\
\text { narrativa. }\end{array}$ \\
\hline
\end{tabular}

Fuente: elaboración propia a partir de Reguillo (1992).

Estos hechos permiten ubicar ciertos objetos relacionados específicamente con la complejidad de los procesos de restitución de tierras y la posición que adoptan los diferentes actores. Este tipo de procesos está basado en las prácticas de negociación de la teoría de juegos ganar-perder. La gestión de la restitución de tierras concluye con la resolución de la adjudicación emitida por un juez especializado a partir del análisis de las pruebas (Herrera y Guglielma, 2006). A continuación se señalan los objetos que influyen de forma determinante en el conflicto por la tierra y en el proceso de retorno en la finca El Carpintero, destacando que se trata de elementos que por sus características pueden presentarse en otros procesos similares en el país.

\section{Análisis de resultados}

\subsection{Transacciones de tierra}

Los procesos de despojo conllevan situaciones de informalidad en la tenencia de la tierra, y estas son aprovechadas por personas con poder suficiente como para apoderarse de la misma. En El Carpintero, tras el abandono forzado, se empezaron a realizar reparticiones de tierra sobre las parcelas dejadas que fueron etiquetadas como remanentes. En los materiales audiovisuales las personas explican este proceder destacando que las ventas y los negocios respondían a mejorar su calidad de vida. No obstante, llama la atención que estos argumentos recaen en los procesos de construcción de verdad y tienden a negar la existencia del sujeto desplazado. Esto es muy interesante a la hora de analizar los escenarios de retorno, porque aparece de manera constante la negación de los hechos de violencia, las razones objetivas que llevaron al desplazamiento y, por ende, se trata de un intento de anulación del otro que reclama la tierra. Esto ubica el fenómeno en la estructura del desplazamiento forzado y en la construcción de identidades que buscan imponerse en un espacio de poder.

El tema de cómo se construye este imaginario entre los sujetos en conflicto (segundos ocupantes, ocupantes de mala fe y reclamantes de tierras) va más allá 
incluso del tipo de restitución que se defiende, ya sea como una restitución fina, es decir, devolver la tierra para fomentar su uso con prácticas económicas centradas en el desarrollo empresarial, o como una restitución gruesa, la que reclama el derecho de las víctimas y la centralidad del campesino en la distribución de la tierra (Uprimny y Sánchez, 2010).

Por el contrario, tomando el escenario concreto del retorno y la restitución de tierras en espacios donde diferentes actores tienen un claro interés por ejercer el poder, hay situaciones donde no solo se trata de regresar, sino también del riesgo de volver a condiciones previas de privaciones materiales y discriminación (Uprimny y Sánchez, 2010). En este sentido, hay un "campo emergente» por explorar: las transiciones o los cambios que el retorno y la restitución de tierras demanda en los espacios de poder y las identidades en pugna en los escenarios de transición de la guerra a la paz.

En El Carpintero no hay evidencia de desplazamiento forzoso [...], entonces ya empezamos como a mejorar nuestra condición de vida, pero para eso tocó empezar a hacer ventas, y por eso aparecen esas cantidades de ventas [...] ¿porque tantas ventas tengo de esa manera?, yo tengo un hijo haciendo la carrera de oficial del ejército, es una carrera [...] supremamente costosa [...] debido al gasto $[\ldots]$ fui vendiendo parcelas. (DOC/P8:28) ${ }^{2}$

Situaciones como estas explicitan el contexto enunciativo de la negación de lugares como un tema central en el conflicto por la tierra. Ello se acompaña con la idea de que los procesos de tránsito a la reinserción no se producen solo en el caso de excombatientes a la vida civil (Lara, 2016), sino también de la reinserción para la población desterrada en términos de ciudadanía política (Salgado, 2012) o por las particularidades de adaptación y reintegración social que se demandan en términos laborales (Mestries, 2015)

En el fragmento citado aparecen dos elementos de negación que se vinculan con el uso de los terrenos de El Carpintero: por un lado, la legitimización de la venta desde una dimensión de necesidad personal y, por otro, la idea de negar evidencias del desplazamiento. Sin entrar a discutir la validez de lo que plantea el relato (tarea de un juez), lo interesante es destacar los lugares de negación del sujeto desterrado. Ya se ha mencionado que estos lugares constituyen una "categoría emergente», puesto que aparecen en las narraciones como relatos viciados por la falsedad para imponer una identidad que justifique o explique prácticas materiales sobre la tierra. Asimismo, pueden darse en relación con otro tipo de conflictos o escenarios, tal como sucedió con gobiernos anteriores, donde la negación discursiva de la existencia del conflicto armado provocó la intensificación de la guerra (Betancur, 2010; Jiménez y González, 2012).

Los lugares de negación manifiestan espacialmente lo que en términos de la historia se ha conocido como «la lucha de los conceptos adecuados»

2. La cita indica el número de DP y el número de la cita, a la que posteriormente se le asignó un código. 
(Koselleck, 1993: 108). Es decir, aquellas denominaciones que configuran los contextos sociopolíticos (Betancur, 2010) y propician acciones de poder sobre el espacio. Esto se empieza a dar en los procesos de restitución de tierras y también en el debate político a nivel nacional. Es lo que han pretendido algunos líderes políticos al manifestar que no hay despojadores sino ocupantes de buena fe, y que, al contrario, hay falsas víctimas y reclamantes. Lo que se resalta es que la negación se localiza y se representa en las dinámicas territoriales.

La otra tierra quedó abandonada de la gente que se fue. Éramos 85 familias en total, la mayor parte de la gente se fue; aquí no quedamos sino 20 familias realmente. Nosotros arrendamos esa tierra en un comienzo para poder sobrevivir porque aquí no teníamos de qué vivir, aquí no había agricultura. (DOC/P9:22)

De manera implícita se relata la negación del desplazamiento, se recalca un perfil de voluntariedad. Cuando se afirma que la gente se fue no es una expresión inocente en tanto niega una realidad violenta vivida por 65 familias. Esto llama la atención teniendo en cuenta la presencia y el dominio de grupos paramilitares en la zona. La legitimación de acciones en el terreno de la construcción de la verdad puede orientar ciertos sesgos si no hay un protocolo claro en las inspecciones, situación que se observa en los vídeos.

Las transacciones de tierra son la expresión material de los lugares de negación, problema que radica en la acumulación de tierras por parte de una sola familia. Así, por ejemplo, 462 hectáreas pertenecen a una sola persona a partir de diferentes negocios. Ante esto, la inspección es interpretada por algunos como una oportunidad para justificar las razones de esta injusta distribución con argumentos planteados desde el proceso de construcción de la verdad.

Sin ninguna presión, sin amenaza ninguna nos dice qué les parece a ustedes si yo me hago cargo del impuesto predial y lo pago y que ustedes me reconozcan un porcentaje, nosotros optamos cada uno por entregarle a él una hectárea y media para que él iniciara la situación del impuesto predial [...] pero hago saber [...] lo hicimos así bajo un documento que hicimos en Cabuyaro que fuimos todos. Allí quedó palpado cuál era la negociación sin ninguna presión de parte de él [...]. (DOC/P12)

\subsection{Mejoras}

La inspección da lugar a que las personas residentes en el predio puedan explicar las actividades que han llevado a cabo en la finca, lo que determina la inversión económica realizada. Muchos interpretan esto como una cuestión importante para entender el conflicto. El lugar desde donde se plantean estas consideraciones suele recaer en la lógica de la negociación ganar o perder, en la medida en que algunos campesinos, después de conocer que la finca entraba en el proceso de restitución, hicieron caso omiso de mantenerse al margen de cualquier usufructo que se pudiera realizar sobre aquella. 
Por el contrario, se observa que muchas personas deciden ampliar la inversión en la finca comprando ganado, ampliando cultivos, mejorando la vivienda, etc., bajo la estrategia de que, si abandonan el predio, tienen derecho a una compensación económica sustantiva. Esto, tal como afirmó el abogado de restitución de tierras, promueve que los sujetos procesales, principalmente los segundos ocupantes, siempre aumenten salvo que no se actúe inmediatamente en los procesos de restitución. Las cifras revelan la lentitud del proceso: en abril de 2016, de 87.118 solicitudes de restitución solamente el 3,4\% habían sido resueltas, y en el departamento del Meta, de 5.712, solo un 1,8\% (Fundación Forjando Futuros, 2016).

En las diligencias judiciales [...] la principal preocupación es que [...] el número de sujetos procesales aumenta, lo que indica que, a partir del desplazamiento, diferentes personas han venido ocupando el predio, ya sea de buena o mala fe. La posesión se quiere justificar por casas improvisadas y aparentes negocios [...] de una familia que presuntamente se aprovecha de la situación. (DOC/P13:4)

Estas circunstancias las mencionan segundos ocupantes en otros procesos de retorno, como en la experiencia de Bosnia Herzegovina, para referir las dificultades de aplicabilidad de las normas tras los Acuerdos de Dayton (Tuathail, 2010), o en términos de garantías limitadas de seguridad, propiedad y empleo para la población que retornó (Hadzic, 2007).

De hecho, los Principios Pinheiro valoraron la situación de ocupantes secundarios a partir de la experiencia positiva sudafricana que contempló el retorno desde la justa reparación, ya que permitió gozar del derecho de reparación sin necesidad de que los titulares regresaran a sus casas o tierras. Por contraste, en Kosovo tan solo el $12 \%$ de la población desplazada logró retornar, debido a que buena parte se sentía amenazada (ONU Hábitat, 2007; Pavlakovi, 2000).

Es preciso aclarar que la restitución de tierras forma parte del proceso de retorno, siendo este un movimiento que implica regresar al punto de partida, $\mathrm{y}$, a su vez, es una solución jurídica. Ambos, retorno y restitución de tierras, forman parte de la identidad del lugar, del sentido del lugar y remiten a otros términos que en la literatura científica se asocian con la apropiación y la pertenencia, con la territorialidad en un sentido afectivo. Así, la restitución y el retorno aparecen como derechos que se complementan y deben dar lugar a políticas públicas diferentes, aunque relacionadas. En todo caso, la restitución debe darse, mientras que el derecho al retorno debe estar presidido por los «principios de voluntariedad, seguridad y dignidad» (Gómez, 2010: 25).

Una de las aristas más conflictivas en el proceso de restitución de tierras asociada al retorno es la de las mejoras. Este tema se plantea con preguntas simples pero importantes a la hora de resolver el litigio: «¿qué hacer con los predios en donde se presentan mejoras y que son objeto de restitución?»; «es necesario plantear una compensación por estas mejoras?», y "ise puede decir que, como estas mejoras han generado un beneficio directo, no hay lugar para una compensación?». 
Estábamos sembrando arroz y ahí fue cuando llegaron los de restitución de tierras y tuvimos una reunión en el colegio [...] nos dijeron que si la línea llegaba a pasar por la mitad de la casa nos tumbaban eso [...], que si la parcela mía resultaba quedando en otro lado yo tenía que abandonar esto que no me reconocían nada que se perdía eso. Entonces pues a uno lo desaniman, entonces hemos aflojado el trabajo, porque de todas maneras sabemos que esta tierra no la merecemos. (DOC/P6:17)

Asumir el esfuerzo de las mejoras cobra mayor importancia para los opositores si se tienen en cuenta las condiciones geográficas del terreno e incluso el contenido afectivo en la vocación agrícola del campesinado.

Esto era solo sabana, inicialmente sembré arroz [...] fue un descalabro [...] estas tierras [...] no sirven para el cultivo [...], sembré también caña difícilmente se dio porque es mucha la plaga [...], entonces aquí no nos sirve realmente la agricultura, por eso yo me alejé de esa parte. El poco capital que tenía lo absorbió en ese entonces lo que yo empecé a sembrar [...], logré sembrar pasto ahí como lo ven y en el año 2011, cuando vino la restitución por primera vez, nos echó los ánimos abajo, porque nosotros veníamos trabajando fuertemente la tierra y entonces ellos nos dijeron que nosotros no sabríamos por donde iban a pasar los linderos y que nos iban a echar a un sorteo, entonces [...] aflojamos el trabajo que veníamos realizando [...]. (DOC/P728)

\subsection{Segundos ocupantes}

El tema de los segundos ocupantes constituye una de las críticas más importantes en los procesos de restitución de tierras, pues es un limitante importante del retorno sin nuevas victimizaciones. Dentro de este grupo se encuentran «compradores de buena fe» cobijados legalmente por diferentes compensaciones, "colonos» que invaden las tierras abandonadas, "compradores» que se aprovechan de la situación derivada del desplazamiento forzado e incluso «ocupantes adscritos como víctimas del conflicto".

En algunas situaciones descritas en la inspección ocular se vuelve a recurrir al escenario de la verdad para justificar la compra de un terreno. Así, algunos manifiestan conocer lo que ocurría en el predio y las condiciones que implican una transacción; otros, por su parte, manifiestan su desconocimiento. En el material audiovisual se pudieron identificar 13 núcleos familiares considerados segundos ocupantes. La mayoría establecieron negocios de compra con personas que habían acumulado gran parte de los terrenos de la finca, por lo que existía una relación entre la promoción de la ocupación de la finca y los acumuladores de tierra.

En el fondo hay una recuperación de la memoria que busca rescatar lo sucedido en el predio. Esto se vincula a la idea de lugar de negación y al conflicto que podría darse entre despojados y despojadores al compartir un mismo espacio después de los hechos victimizantes, tal como se ha estudiado para los refugiados en Canadá (Riaño y Villa, 2008). Así, «los recuerdos actúan como 
materia prima de la narrativa, es decir, la alimentan, la llenan de contenido, la expresan vivencial y le asignan significados» (Garzón, 2014: 71). Esto lo enmarca la autora como narrativas del retorno, pero va más allá de un escenario de construcción de subjetividades y de planos discursivos, puesto que se refleja en acciones concretas, como la justificación de ocupaciones, ventas indebidas de lotes y promoción de desplazamientos forzados.

Ello explica mejor la frecuencia de "códigos» asignados en los documentos primarios. Para los desterrados el paramilitarismo ocupa un lugar privilegiado en sus narraciones, para los ocupantes este es un aspecto sin relevancia, porque la relación con el lugar es otra y la agenda que prioriza tiene que ver con la justificación de las transacciones de tierra. Lo anterior es más interesante si se vincula a lo ocurrido en otros procesos de retorno: «los estudios realizados en Malawi y en Europa han demostrado que los refugiados tienden a creer más en la información de personas conocidas y familiares que en la trasmitida institucionalmente» (Stepputat, 2004: 8). Por su parte, la identidad de los desterrados se da en un escenario de tensión entre la narrativa de un pasado violento y el marco institucional que los encasilla como sujetos de atención especial.

\subsection{Actores empresariales de la palma aceitera y el petróleo}

Algunos autores sugieren que hay una relación considerable entre los cultivos de palma y el desplazamiento generado por la acción de grupos paramilitares. Un amplio estudio estadístico permite explicar esta tendencia en todo el país, subrayando la incidencia en el departamento del Meta (Rey, 2013). Los testimonios de los segundos ocupantes señalan que, de las 1.038 hectáreas de El Carpintero, 602 han sido dedicadas al monocultivo de palma y 462 han quedado como propiedad de una sola persona.

La presencia de empresas palmeras en la región ha implicado una dinámica de reclutamiento de mano de obra, incluidos muchos de los segundos ocupantes. La consecuencia inmediata del «reclutamiento» determina dos particularidades: por un lado, el abandono de actividades campesinas y, por otro lado, el favorecimiento de una dinámica de repoblamiento, ya que, al otorgar contratos de trabajo, las empresas están obligadas a generar cupos de empleo destinados a gente de la región, para ello las empresas obligan a los trabajadores a demostrar su lugar de residencia. En el caso de El Carpintero muchas personas utilizaron documentos relacionados con la compra de parcelas para demostrar que eran residentes.

Como se mencionó, los objetos que se destacan en el momento de sistematizar las inspecciones oculares y la manera como son asumidos por los actores permiten identificar varios elementos transversales que configuran el escenario territorial del retorno. Estos comparten dimensiones conflictivas de peso diferente, y de ellos se destacan al menos seis componentes (figura 4).

$\mathrm{Al}$ profundizar en el tema de las transacciones de tierras se establece que el mismo está relacionado directamente con la tenencia informal y el usu- 
Figura 4. Objetos transversales en los escenarios de retorno y conflictos por la tierraFuente:

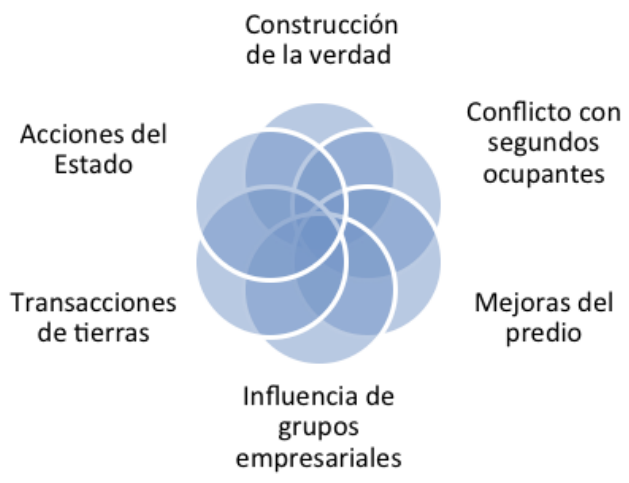

Fuente: elaboración propia.

fructo de los remanentes. Las transacciones de tierra se dieron en un marco de informalidad adelantada, en su mayoría en oficinas de notariado y registro que terminaron avalando una amplia concentración de la tierra en manos de una familia. En la finca El Carpintero se desarrollaron ventas de lotes en los cuales se ubicaron familias consideradas segundos ocupantes. En este grupo algunas hicieron compras conociendo la historia y el litigio existente en el predio, en otras compras se desconocían estos factores. Para la resolución del conflicto es importante crear instrumentos de clasificación que permitan diferenciar a los ocupantes de mala fe de los engañados, que viven en situación vulnerable.

El tema de las mejoras es central si se realiza una nueva distribución del terreno de la finca, ya que el deseo de propiedad de las personas retornadas implicaría un proceso de asentamiento sobre terrenos que han sido ocupados por diferentes procedimientos desde el momento del desplazamiento forzado. Igualmente, la influencia de grupos empresariales ha sido determinante en los patrones de ocupación y uso del suelo. Así, los cultivos de palma se han beneficiado de la mano de obra de residentes en El Carpintero y de la acumulación indebida de algunas familias a partir de las transacciones.

Todos estos escenarios se dan al margen de la construcción de la verdad, las transacciones de tierra, la clarificación de linderos, los hechos de violencia, la convivencia de los grupos empresariales y paramilitares, entre otros, aún cuando son esenciales para generar un proceso efectivo de reparación y retorno, incluso si este no constituye una opción real. Aquí es relevante no simplificar el proceso del retorno al lugar de expulsión, sino dimensionar todas las fracturas espaciales que estos procesos encarnan y, por supuesto, los lugares de negación, ya que, cuando se habla de «la necesidad de la verdad», se prioriza la eliminación de esas «negaciones» que en El Carpintero terminan invisibilizando las identidades de los sujetos reclamantes. Este es uno de los conflictos de poder que afloran en los territorios del retorno. 


\section{Conclusiones}

Mediante un análisis de documentos cualitativos referidos al caso El Carpintero se han diferenciado cuatro temas en el proceso de restitución de tierras en el contexto del retorno de población desplazada: transacciones de tierras, mejoras para explotar la tierra, segundos ocupantes y actores empresariales. Los actores del conflicto atribuyen un valor diferente a cada uno de ellos según la posición que ocupan y la relación que tienen con el territorio. Así, para las personas desterradas todos dependen de la presencia paramilitar, pero para los segundos ocupantes y opositores hay toda una justificación verbalizada que justifica acciones de ilegalidad en las transacciones de tierras.

El conflicto descrito evidencia la consolidación de la idea del territorio como espacio de poder donde confluyen aspectos territoriales propios de la dinámica del conflicto armado y el sentido de lugar atribuido por los propios protagonistas del proceso de restitución de tierras (desterrados, opositores y ocupantes). En este sentido, del análisis de los diferentes documentos, emerge la categoría de lugares de negación, entendida como aquella narración que niega desde la construcción de la verdad las identidades de los sujetos desterrados y justifica acciones concretas en el territorio. El hecho de ser una «categoría emergente» la convierte a su vez en un concepto con un importante potencial investigativo.

El retorno se vincula aquí a un tránsito que va desde los lugares desconocidos que caracterizan la vivencia de los desterrados a la de sus lugares demandados. Particular interés manifiesta esta idea en tanto se trata de una reflexión necesaria para comprender las dinámicas de transición desde escenarios caracterizados por la violencia hasta escenarios de construcción de paz.

Es necesario impulsar investigaciones sobre las dinámicas concretas de los procesos de restitución de tierras y las tensiones propias entre ocupantes y reclamantes de tierras. La interacción entre estos actores y la gestión adecuada de la materia de discusión implica reconocer que, cuando la opción de los segundos es retornar, las acciones a desarrollar en el territorio van más allá de la resolución jurídica del conflicto.

\section{Referencias bibliográficas}

Barreto, Liliani; Bechara, Salomon; Bogliacino, Francesco; ChÁvez, Natalia; JiméneZ, Laura; Martínez, Patricia y VelázQuez, Olga (2016). Retos de la integración en comunidades retornadas: Análisis del caso de Las Palmas, Bolivar. Bogotá: Centro de Investigaciones para el Desarrollo (CID).

Betancur, Juan (2010). «Conflicto Armado Interno vs. Amenza Terrorista». Reflexión Politica, 12 (24), 68-77.

CANTOR, David (2010). Estrategias para manejar la inseguridad: El retorno de los desplazados en Colombia. University of London. Institute of Commonwealth Studies.

CAVIDA (2002). Somos tierra de esta tierra. Chocó.

Centro Nacional de Memoria Histórica (CNMH) (2016). Tierras y conflictos rurales. Historia, politicas agrarias y protagonistas. Bogotá: Centro Nacional de Memoria Histórica. 
CHÁveZ, Yuri y Falla, Uva (2005). «Representaciones sociales acerca del retorno en población en situación de desplazamiento asentada en el municipio de Soacha». Tabula Rasa, 3, 271-292.

Churruca, C. y Meertens, D. (eds.). Desplazamiento forzado en Colombia. Prevenir, asistir, trasformar: Cooperación internacional e iniciativas locales. Bogotá: La Carreta Social.

Dahlman, Carl y Tuathail, Gearóid (2005). «The legacy of ethnic cleansing: The international community and the returns process in post-Dayton Bosnia-Herzegovina». Political Geography, 24 (5), 569-599.

Defensoría del Pueblo (2016). Informe de riesgo, 19-16a. I (31 de mayo).

DíAZ, Catalina y ZamorA, Angélica (2010). Reparar el destierro. Bogotá: Centro Internacional para la Justicia Transicional.

DíAZ, Íngrid (2016). «Colonización sin hacha: Narrativas estatales sobre región, naturaleza y desarrollo de la altillanura colombiana». En: JiMENO, M. y VARELA, D. (eds.). Etnografías contemporáneas III: Las narrativas en la investigación antropológica. Bogotá: Universidad Nacional de Colombia, 396.

EGEA, Carmen y SOLEDAD, Ivan (2007). «Territorio, conflictos y migraciones en el contexto colombiano». Cuadernos Geográficos, 40.

EgEA, Carmen; Nieto, José y JiméNEZ, Francisco (2002). «El estudio del retorno: Aproximación bibliográfica». Migraciones y Exilios, 3, 141-168.

EsPinEL, Juan y PINZÓN, Viviana (2014). El despojo como crimen de Estado, documentando "El Carpintero». Bogotá: Universidad Pedagógica Nacional.

FAJARDO, Darío (2004). El conflicto armado y su proyección en el campo, 67-105. Recuperado de <http://www.plagios.org/wp-content/uploads/2016/08/Anexo-4.-Elconflicto-armado-en-Colombia.-Fajardo-2004.pdf>.

FUNDACIÓN FORJANDO FUTUROS (2016). La restitucion de tierras no avanza: Análisis de 1.500 sentencias. Medellín.

Gammage, Sarah y Worley, Heidi (2002). «Despues de la paz: Los desafíos de la reintegración para las poblaciones afectadas por la guerra». En: Retorno con integracion: El reto despues de la paz. San Salvador: UNDP/FLACSO.

GARZÓN, María (2014). «Las narrativas del retorno». Encuentros, 12 (2), 67-77.

GÓMEZ, Augusto (1998). «La guerra de exterminio contra los grupos indígenas cazadores-recolectores de los llanos orientales (siglo XIX y XX)». Anuario Colombiano de Historia Social y de la Cultura, 25, p. 351-376. $<$ https://doi.org/10.15446/achsc>

GÓMEZ, Felipe (2010). «La restitución de la tierra y la prevención del desplazamiento forzado en Colombia». En: Churruca, C. y Meertens, D. (eds.). Desplazamiento forzado en Colombia. Prevenir, asistir, transformar: Cooperación internacional e iniciativas locales. Bogotá: La Carreta Social.

Hadzic, Lejla (2007). «As Dayton Undergoes Proposals for Reform, the Status of Freedom of Movement, Refugee Returns, and War Crimes in Bosnia and Herzegovina». Human Rights Review, 9 (1), 137-151.

Hanafi, Sari (2003). The Sociology of Return: Palestinian Social Capital, Transnational Kinships and the Refugee Repatriation Process. American University of Beirut.

Herrera, Adriana y Da Passano, María Guglielma (2006). Manejo alternativo de conflictos de tenencia de la tierra: Manuales sobre tenencia de la tierra 2. Roma: Organización de las Naciones Unidas para la Agricultura y la Alimentación.

IBÁÑEZ, Ana (2004). «Génesis del desplazamiento forzoso en Colombia: Sus orígenes, sus consecuencias y el problema de retorno». Coyuntura Social, 30, 87-104. 
- (2009). «Los programas de retorno para la población desplazada en Colombia». En: RodríGUEZ, C. (ed.). ¿Cómo superar el desplazamiento?: Jurisprudencia constitucional y politicas públicas en Colombia. Bogotá: Universidad de los Andes, $1-41$.

IbáÑEZ, Ana y Querubín, Pablo (2004). Acceso a tierras y desplazamiento forzado en Colombia. Bogotá: CEDE Universidad de Los Andes.

Isotalo, Riina (2005). «Palestinian return: Reflections on unifying discourses, dispersing practices and residual narratives». En: Many routes to Palestine: The Palestinian return, forged transnationalism and gender. Helsinki: University of Helsinki. Institute of Development Studies.

JimÉNEZ, Francisco y GONZÁLEZ, Álvaro (2012). «La negación del conflicto colombiano: Un obstáculo para la paz». Espacios Públicos, 15, 9-34.

Koselleck, Reinhart (1993). Futuro pasado. México: Paidós.

LARA, Luz (2016). "¿Y después de la guerra qué?: Avatares en el tránsito a la vida civil de jóvenes desmovilizados de las FARC». Universitas Humanística, 82.

LA Rota, María y SAlCEdo, Leonardo (2016). «La Altillanura: Desafíos y posibilidades del ordenamiento territorial en la nueva frontera agrícola colombiana». En: DuARTE, C. (ed.). Desencuentros territoriales. Tomo II, Caracterización de conflictos territoriales en las regiones de la Atillanura, Putumayo y Montes de María. Bogotá: Instituto Colombiano de Antropología e Historia.

LEGRAND, Catherine (2009). «Los antecedentes agrarios de la violencia: El conflicto social en la frontera colombiana, 1850-1936». En: SÁNCHEZ, Gonzalo y PEÑARANDA, Ricardo (eds.). Pasado y presente de la violencia en Colombia. Medellín: La Carreta Histórica, 119-137.

López, María (2007). «Repatriar víctimas del conflicto colombiano: Una propuesta inviable». Aldea Mundo, 12, 79-82.

MaCHADO, Absalón (2004). Tenencia de tierras, problema agrario y conflicto. Bogotá. Recuperado de <https://vertov14.files.wordpress.com/2012/01/absalon-machadotenencia-de-tierras-problema-agrario-y-conflicto.pdf>.

MARULANDA, Elsy (1988). Colonización, hacienda y movilización campesina: El caso de Sumapaz. Bogotá: Universidad Nacional de Colombia.

MesTrIES, Francis (2015). «Los migrantes de retorno ante un futuro incierto». Sociológica, 78, 171-212.

Molano, Alfredo (2014). «El proyecto Nación y el País Olvidado». En: Mora, D. y SÁNCHEZ, N. (eds.). Cartografías de la paz: Una mirada crítica al territorio. Bogotá: Universidad de la Salle, 89-105.

ONU HÁBITAT (2007). Manual sobre la restitución de las viviendas y el patrimonio de refugiados y personas desplazadas.

PASCUAL, Àngels (2009). «La noción de retorno: Sentido(s) en contexto migratorio actual». En: CHECA, F.; CHECA, J. y ARJONA, A. (eds.). Las migraciones en el mundo. Barcelona: Icaria, 159-173.

PaVlaKovi, Vjeran (2000). "Refugee Returns in Kosovo: Learning from the Mistakes in Bosnia and Croatia». Human Rights Review (enero-marzo), 108-112.

PeÑa, Abilio (2004). «Éxodo, retorno y resistencias». Theologica Xaveriana, 149, 55-72. Perdomo, Hernando y Clavijo, Claudia (1999). Colombianos en España. Madrid: ACCEM.

Piedad, Luz; Manrique, Daniel; Constanza, Delma y Pulido, Bleky (2006). Retornos sin principios, desplazamientos sin final: Evaluación de la politica de retorno del gobierno de Alvaro Uribe. Bogotá: ILSA. 
RAMíREZ, Luis (2015). «Revisión a la implementación de los programas de retorno: Una mirada a partir de tres estudios de caso en el Oriente Antioqueño». El Ágora USB: Revista de Ciencias Sociales, 15 (2), 447-456.

Reguillo, Rosana (1992). El vídeo, un dispositivo de investigación. Recuperado de $<$ https://www.researchgate.net/publication/27390070_El_video_un_dispositivo_de_investigacion>.

ReY, Camilo (2013). «Análisis espacial de la correlación entre cultivo de palma de aceite y desplazamiento forzado en Colombia». Cuadernos de Economía, 32 (61), 683-718. $<$ https://doi.org/10.15446/cuad.econ>

Riaño, Pilar y Villa, María (2008). Poniendo tierra de por medio: Migración forzada de colombianos en Colombia, Ecuador y Canadá. Medellín: Corporación Región.

RodríGUEZ, Ivonne (2014). «Despojo, baldíos y conflicto armado en Puerto Gaitán y Mapiripán (Meta, Colombia) entre 1980 y 2010». Estudios Socio-Jurídicos, 16 (1), 285-338.

Romero, Mauricio (2010). «Desprotección, estigmatización y despojo: Un Estado regional depredador en el norte del departamento del Choco». En: CHURRUCA, C. y Meertens, D. (eds.). Desplazamiento forzado en Colombia: Prevenir, asistir, trasformar, cooperación internacional e iniciativas locales. Medellín: La Carreta.

Rousseau, Cécile; Morales, María y Foxen, Patricia (2001). «Going Home: Giving Voice to Memory Strategies Of». Culture, Medicine and Psychiatry, 25, 135-168.

SAIZ, María (2001). Las estrategias de retorno y reubicación frente a la problemática del desplazamiento: El caso del municipio de Quibdó-Chocó. Bogotá: Universidad Nacional de Colombia.

SALAZAR, Lorena (2009). Posible aplicación del concepto de refugiado ambiental en los procesos de repatriación a la luz del caso Colombo-Ecuatoriano del 2007. Universidad del Rosario.

SAlgADO, Henry (2012). «Destierro y suspensión de la ciudadanía: Hacia una compresión antropológica del refugio forzado. El caso colombiano». En: Silva, S. A. (ed.). Migraçôes na Pan-Amazônia: Fluxos, fronteiras e processos socioculturais. São Paulo: FEPEAM, 144-165.

SÁNCHEZ, Lina (2008). «Éxodos rurales y urbanización en Colombia». Bitácora, 13 (2), 57-72.

SANTACRUZ, Lucy (2013). Expectativas de futuro de la población colombiana refugiada en las ciudades de Ibarra, Lago Agrio y Esmeraldas. Ecuador: FLACSO ACNUR.

SOLEDAD, Iván (2009). Desplazamiento interno en Colombia: La situación de los desplazados en el Catatumbo. Universidad de Granada.

Stepputat, Finn (2004). "Dynamics of Return and Sustainable Reintegration in a "Mobile Livelihoods" - Perspective». Diis Working Paper, 10.

STEYN, Melissa y GRANT, Terri (2007). "A real bag of mixed emotions: Re-entry experiences of South African exiles». International Journal of Intercultural Relations, 31 (3), 363-389.

TUATHAIL, Gearóid (2010). «Localizing geopolitics: Disaggregating violence and return in conflict regions». Political Geography, 29 (5), 256-265.

UprimnY, Rodrigo y SÁnCHEZ, Nelson (2010). «Los dilemas de la restitución de tierras en Colombia». Estudios Socio-Jurídicos, 12 (2), 305-342.

VARÓN, María (2011). «Desplazados, Retornados, migraciones internas y re-configuraciones territoriales». En: X Congreso Nacional de Sociología de Colombia. 
VelÁsquez, Blanca (2005). Documento Pedagógico \# 17 El Retorno: ¿Un Imposible? Santiago de Cali: Capacitación.

VIDAL, Roberto (2007). Derecho global y desplazamiento interno: Creación, uso y desaparición del desplazamiento forzado por la violencia en el Derecho Contemporáneo. Bogotá: Pontificia Universidad Javeriana.

ZuLUAGA, Jaime (2009). La guerra interna y el desplazamiento forzado. Bogotá: Universidad Nacional de Colombia. Recuperado de: <http://antigua.mamacoca.org/ docs_de_base/Cifras_cuadro_mamacoca/Jaime_zuluaga.pdf s. 